\title{
Small bowel stenosis after blunt abdominal trauma: a case report
}

\author{
Kazushi Hara, Manabu Yamamoto ${ }^{*}$, Teruhisa Sakamoto, Ken Sugezawa, Chihiro Uejima, Akimitsu Tanio, \\ Yoichiro Tada, Takehiko Hanaki, Kozo Miyatani, Joji Watanabe, Kyoichi Kihara, Naruo Tokuyasu, Shuichi Takano, \\ Soichiro Honjo and Yoshiyuki Fujiwara
}

\begin{abstract}
Background: Small bowel stenosis after blunt abdominal trauma is relatively rare, and progression from trauma to bowel stenosis might sometimes be delayed. Herein, we report the case of a patient who was diagnosed with small bowel stenosis relatively early and received laparoscopic surgery.

Case presentation: An 18-year-old Japanese male was in a traffic accident and was urgently transported to our hospital. On arrival, he was admitted with right kidney and right adrenal injury and abdominal aortic aneurysm. On hospital day 13, he vomited during conservative treatment without surgery, and computed tomography revealed small bowel stenosis and dilatation of the oral-side small bowel. No improvement with the ileus tube occurred, and he received laparoscopic surgery on hospital day 21. Briefly, the abdominal cavity was observed with a laparoscope. The mesentery was congested, scarring around the stenotic small bowel regions was present, and three stenotic regions were observed $40-50 \mathrm{~cm}$ from the Treitz ligament. The patient received partial resection and anastomosis of the small bowel. The postoperative course was stable, and he was discharged on postoperative day eight.

Conclusions: Most cases of bowel stenosis after abdominal trauma are irreversible and usually require surgical treatment. Therefore, small bowel stenosis should be considered in patients with abdominal symptoms after blunt abdominal trauma.
\end{abstract}

Keywords: Blunt abdominal trauma, lleus, Laparoscopic surgery, Small bowel stenosis

\section{Background}

Gastrointestinal damage due to blunt abdominal trauma often presents with symptoms immediately after injury due to organ rupture or bowel perforation and requires emergent surgery. However, patients rarely develop small bowel stenosis or obstruction several days to months after the initial trauma. Herein, we report the case of a patient with small bowel stenosis on day 13 after blunt abdominal trauma who was successfully treated with partial small bowel resection by laparoscopic assistance.

\footnotetext{
* Correspondence: m.yamamoto@tottori-u.ac.jp

Division of Surgical Oncology, Department of Surgery, School of Medicine,

Tottori University Faculty of Medicine, 36-1 Nishi-cho, Yonago 683-8503, Japan
}

\section{Case presentation}

An 18-year-old Japanese male patient was urgently transported to our hospital following a traffic accident. The patient was sitting in the passenger seat with the seat belt fastened and had a car-to-car accident. The patient was diagnosed with right kidney injury, right adrenal injury, and abdominal aortic aneurysm and was admitted to the hospital. Intra-abdominal hemorrhage due to renal injury was controlled by endovascular treatment. The abdominal aortic aneurysm was followed without any intervention. Other organs, including the small bowel, did not show any damage on the first computed tomography (CT) examination. The clinical course of the patient was good after these treatments, and food intake was initiated on the tenth hospital day. However, on hospital day 13, the patient vomited bile-like fluid
SpringerOpen

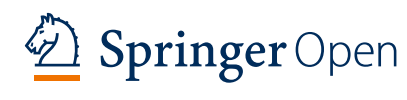

(c) The Author(s). 2020 Open Access This article is licensed under a Creative Commons Attribution 4.0 International License, which permits use, sharing, adaptation, distribution and reproduction in any medium or format, as long as you give appropriate credit to the original author(s) and the source, provide a link to the Creative Commons licence, and indicate if changes were made. The images or other third party material in this article are included in the article's Creative Commons licence, unless indicated otherwise in a credit line to the material. If material is not included in the article's Creative Commons licence and your intended use is not permitted by statutory regulation or exceeds the permitted use, you will need to obtain permission directly from the copyright holder. To view a copy of this licence, visit http://creativecommons.org/licenses/by/4.0/. 


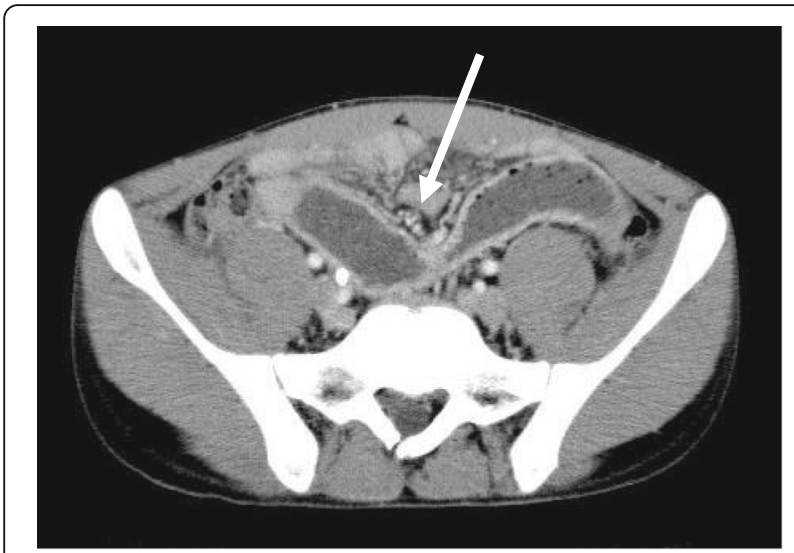

Fig. $1 \mathrm{CT}$ showing stenosis of the small bowel and dilatation of the oral small bowel

twice. He experienced no abdominal pain, and hematological tests did not reveal any abnormal findings. CT showed stenosis and oral-side dilatation of the small bowel (Fig. 1), and he was diagnosed with small bowel obstruction. Although he was conservatively treated with fasting and infusion initially, the CT findings on hospital day 19 did not improve the bowel obstruction; therefore, an ileus tube was placed. The next day, gastrointestinal contrast examination using the ileus tube revealed at least two stenotic regions in the small bowel (Fig. 2). Based on these findings, the patient was diagnosed with small bowel stenosis due to blunt abdominal trauma and received laparoscopic surgery on hospital day 21 .

First, a 12-mm port was placed using the open method in the umbilical site and the abdominal cavity was observed with a laparoscope. A localized area of the mesentery was congested and edematous, and scarring around the stenotic section of the small bowel was

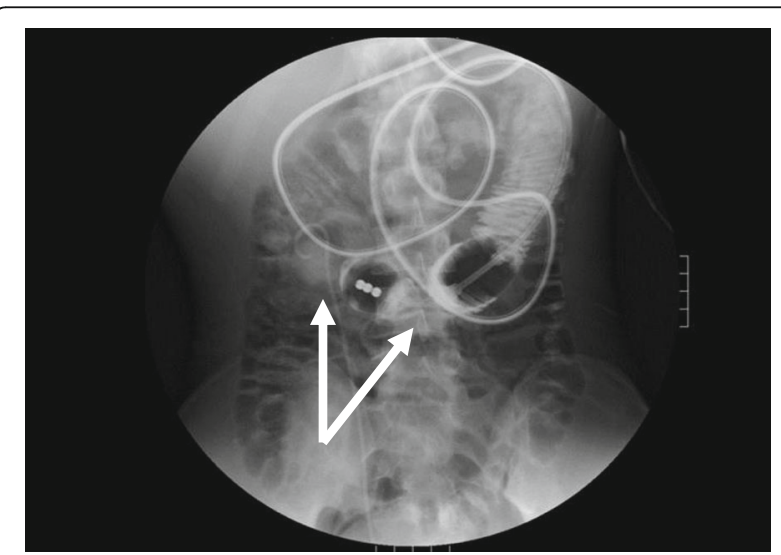

Fig. 2 Gastrointestinal contrast study showing at least two stenotic areas in the small bowel (white arrows) present (Fig. 3a, b). A small incision was made in the umbilicus, and the stenotic sections of the small bowel were brought outside through the abdominal wall. Close observation revealed three stenotic regions which were $40-50 \mathrm{~cm}$ from the Treitz ligament, and partial resection and anastomosis of the small bowel were performed. The operation time was $2 \mathrm{~h}$ and $20 \mathrm{~min}$, and the blood loss was $5 \mathrm{~mL}$.

The excised specimen showed three stenotic regions (Fig. 4). The pathological examination revealed erosion of the mucosa and ulceration; the muscle layer was also destroyed and partially ruptured (Fig. 5a). The strong expansion and hyperplasia of the capillaries, which were recognized as findings of fibrosis, were also observed (Fig. 5b).

The postoperative course was stable, and the patient was discharged on postoperative day eight.

\section{Discussion}

Patients with gastrointestinal damage due to blunt abdominal trauma often present with acute symptoms due to bowel rupture and/or bleeding, usually requiring emergent surgery. However, in rare cases small bowel stenosis or obstruction occurs several days or months after the trauma [1-3]. The underlying causes of trauma-induced intestinal stenosis include altered circulation due to mesenteric damage, direct damage to the intestinal wall and hematoma formation, and inflammatory adhesions [4]. Mesenteric damage causes injury to the mesenteric artery and leads to necrotic changes and ulceration of the intestines due to altered blood flow. During healing, stenosis occurs due to scar contraction. The blood flow dysfunction usually includes the entire intestinal wall circumference, leading to annular stenosis [5]. In the present case, edematous changes were observed in the mesentery, and histological examination showed fibrosis with ulceration and infiltration of the inflammatory cells. Small bowel stenosis was therefore considered to arise from the altered circulation due to mesenteric damage and subsequent scar formation. Given that intestinal stenosis is usually irreversible due to scarring and fibrosis, conservative treatments such as decompression are not applicable, and surgery is required in most cases.

In our case, we performed laparoscopic surgery. If the surgery needs to be performed within a short period after the injury, open surgery may be chosen because of the possibility of damage to other organs and the need for a detailed intra-abdominal search. However, in our case, it had been several days since the injury, and a diagnosis of only small bowel stenosis was made, with no other abnormalities; furthermore, decompression of the small intestine was successful using an ileus tube. Therefore, we selected laparoscopic surgery. The 15- 


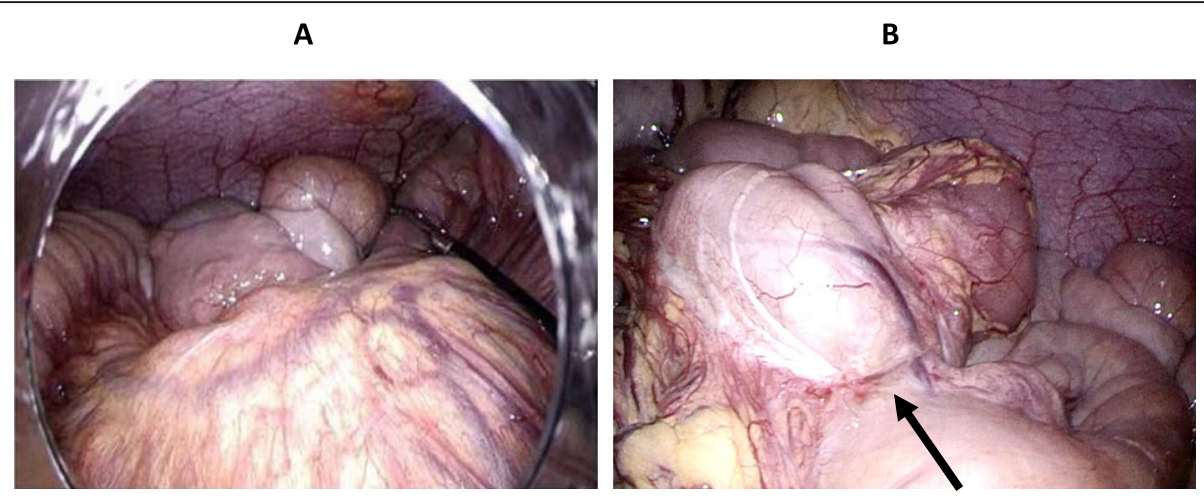

Fig. 3 Intraoperative findings. a Small bowel mesentery is congested. b Note stenosis in the small bowel (arrow)

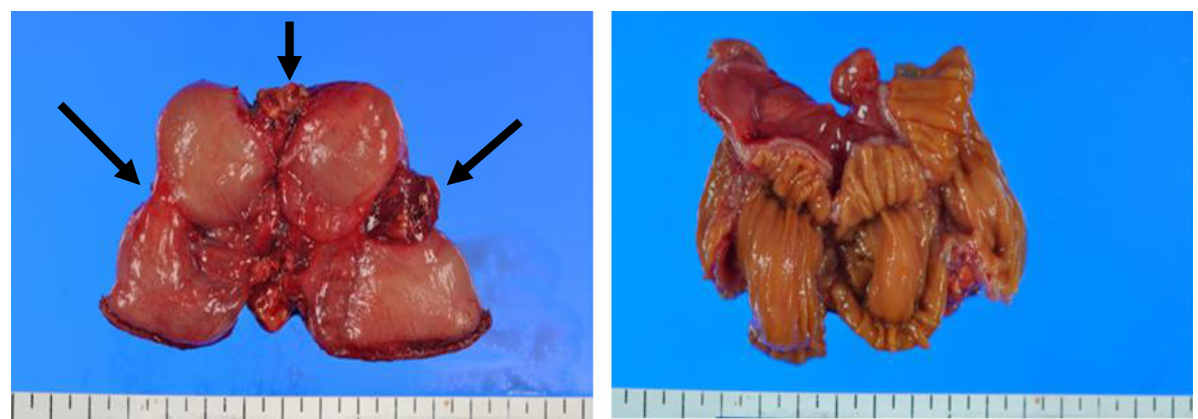

Fig. 4 Resected specimen showing three areas of stenosis
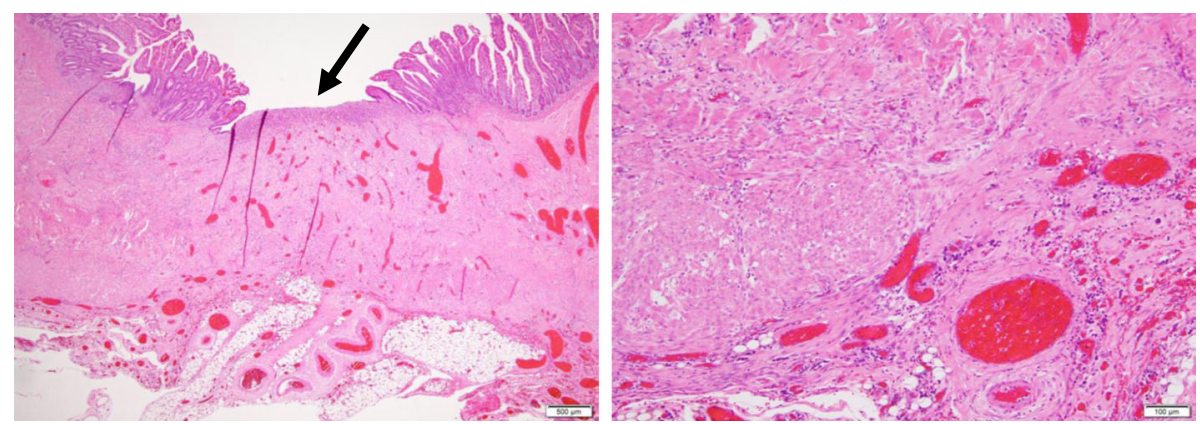

Fig. 5 Histological findings. a Mucosal erosion and ulceration are observed (arrow), and the muscle layer is destroyed and ruptured just below. b Capillary growth and dilatation and fibrosis can be observed 


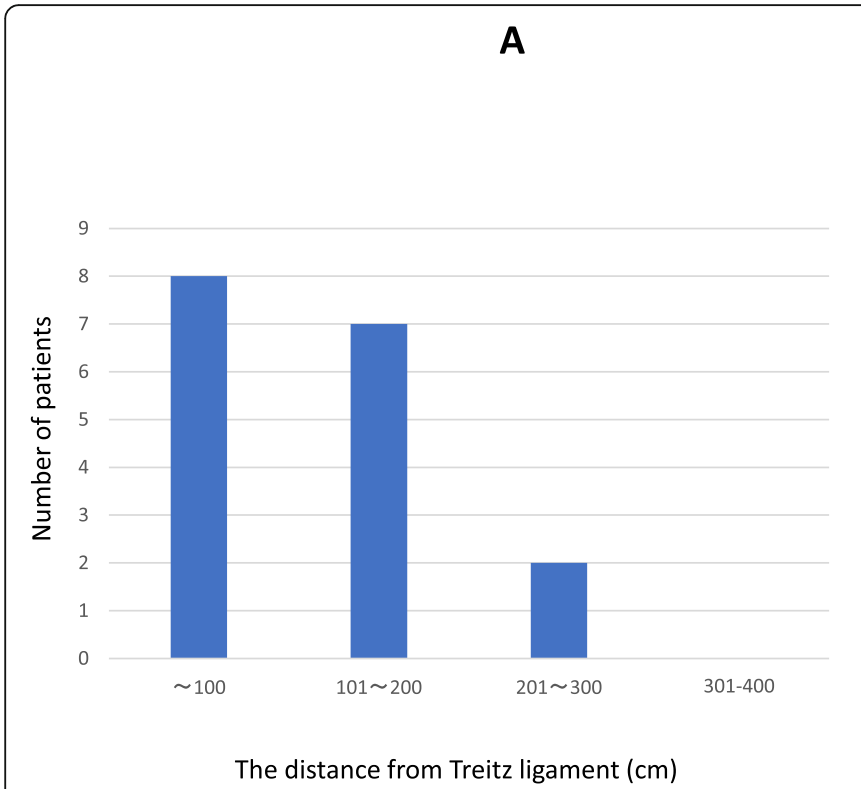

B

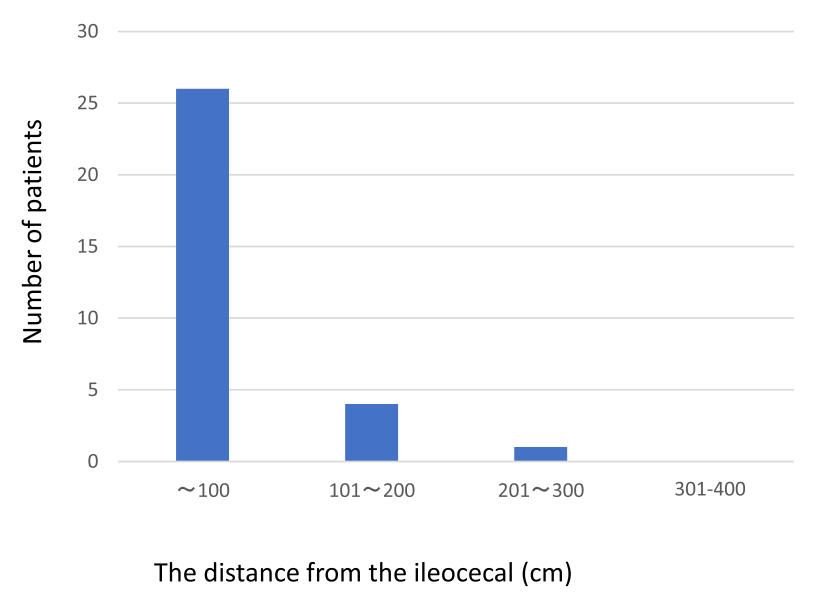

Site of small bowel stenosis after blunt trauma $(n=48)$

Fig. 6 Site of the small bowel stenosis after blunt trauma $(n=54)$. a Distance from Treitz ligament to the small bowel stenosis. $\mathbf{b}$ Distance from the ileocecal valve to the small bowel stenosis

year-old patient underwent partial resection of the small intestine with a 3-cm incision; it was less invasive, and laparoscopic surgery was also useful in terms of integrity.

Bowel stenosis due to abdominal trauma is often located near the body midline such as the upper small bowel and terminal ileum, where the mesentery is relatively fixed [6-8]. Except for the small intestine, stenosis is commonly observed in the duodenojejunal flexion, transverse colon, and sigmoid colon, which are close to the spine, suggesting that gastrointestinal damage might be due to the compression of the affected area between the abdominal wall and spine [9].

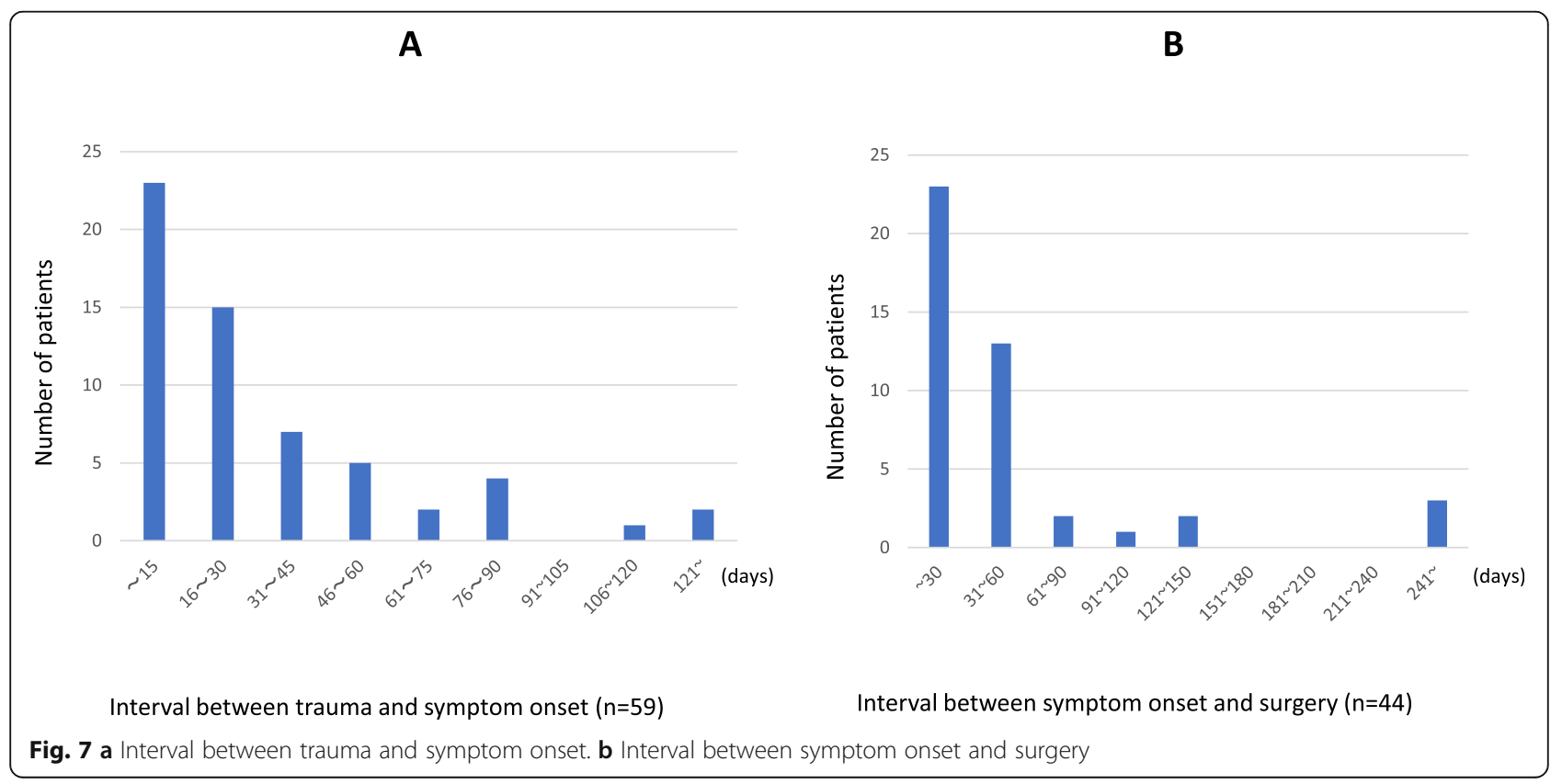


We searched the literature from 1980 to 2018 using the keywords "abdominal trauma," "late onset," and "small bowel stenosis" using the PubMed and the Japan Medical Abstracts Society electronic databases, and the 62 collected cases were reviewed, 47 males and $15 \mathrm{fe}-$ males with an average age of 40.5 (5-80) years. The cause was traffic accidents in 41 of these 62 cases. In $87 \%$ of the cases, the location of delayed small bowel stenosis was within $100 \mathrm{~cm}$ from the ileocecal region and within $200 \mathrm{~cm}$ from the Treitz ligament (Fig. 6). The location of the stenosis was also $40-50 \mathrm{~cm}$ from the Treitz ligament in the present case, consistent with the previous reports. The interval from trauma to symptom onset was within 15 and 30 days in 23 (39\%) and 38 $(64 \%)$ of the cases in the literature, respectively, whereas stenosis occurred after 60 days in $9(15 \%)$ cases. While 23 (52\%) patients received surgery within 30 days from the symptom onset, 21 (48\%) patients did not receive surgery even after the first 30 days (Fig. 7).

Several reasons underlie delayed diagnosis and surgery in these patients. First, temporal conservative treatment might improve symptoms in patients with incomplete stenosis. Additionally, since symptom development takes time, the patient might be handled without the knowledge of prior blunt abdominal trauma if they are treated for stenosis-related symptoms in a hospital other than the emergency hospital handling the initial trauma. Therefore, obtaining detailed medical history on abdominal trauma is important to ensure early diagnosis.

\section{Conclusions}

Post-traumatic intestinal stenosis should be considered in patients with a history of blunt abdominal trauma presenting with abdominal symptoms.

\section{Abbreviations \\ $\mathrm{CT}$ : Computed tomography}

\section{Acknowledgements}

The authors would like to thank Enago for the English language review.

\section{Authors' contributions}

$\mathrm{KH}$ wrote the manuscript and prepared the manuscript under the supervision of MY. MY and TS performed the surgery. Other co-authors discussed the content of the manuscript. All authors read and approved the final manuscript.

\section{Funding}

Not applicable

\section{Availability of data and materials}

All data regarding this paper are available on request.

Ethics approval and consent to participate

Not applicable

\section{Consent for publication}

Consent for publication has been obtained from the patient presented in this report.

\section{Competing interests}

The authors declare that they have no competing interests.

Received: 25 March 2020 Accepted: 14 May 2020

Published online: 26 May 2020

References

1. Kang GH, Jeon TJ, Seo DD, Oh TH, Kim SH, Cho HS, et al. Ileal stenosis occurred 3 months after blunt abdominal trauma. Korean J Gastroenterol. 2011:57:370-3.

2. Bryner UM, Longerbeam JK, Reeves CD. Posttraumatic ischemic stenosis of the small bowel. Arch Surg. 1980;115:1039-41.

3. Prince S, Busharar HAS, AIZoabi OM. Small bowel stenosis following blunt abdominal trauma: a case report. Clin Case Rep. 2017;5:1865-7.

4. Shively E, Pearlstein L, Kinnaird DW, Roe J, Jones CE. Post-traumatic intestinal obstruction. Surgery. 1976;79:612-7.

5. Hirota C, lida M, Aoyagi K, Matsumoto T, Yao T, Fujishima M. Posttraumatic intestinal stenosis: clinical and radiographic features in four patients. Radiology. 1995;194:813-5.

6. Orloff MJ, Charters AC. Injuries of the small bowel and mesentery and retroperitoneal hematoma. Surg Clin North Am. 1972;52:729-34.

7. Marks CG, Nolan DJ, Piris J, Webster CU. Small bowel strictures after blunt abdominal trauma. Br J Surg. 1979;66:663-4.

8. Lien GS, Mori M, Enjoji M. Delayed posttraumatic ischemic stricture of the small intestine. A clinicopathologic study of four cases. Acta Pathol Jpn. 1987:37:1367-74.

9. Williams RD, Sargent FT. The mechanism of intestinal injury in trauma. J Trauma. 1963;3:288-94.

\section{Publisher's Note}

Springer Nature remains neutral with regard to jurisdictional claims in published maps and institutional affiliations.

\section{Submit your manuscript to a SpringerOpen ${ }^{\circ}$ journal and benefit from:}

- Convenient online submission

- Rigorous peer review

- Open access: articles freely available online

High visibility within the field

- Retaining the copyright to your article

Submit your next manuscript at $>$ springeropen.com 